\title{
Enhanced growth of Oriza sativa by endophytic: Bacillus cereus and Paenibacillus polymxya
}

\begin{abstract}
The health growth of Oryza sativa depends on non-excess nitrogen fertilizer, one way to achieve its to inoculate its seed with endophytic plant growth promoting bacteria: Bacillus cereus and Paenibacillus polymxya. In that, sense seeds of $O$. sativa were inoculated by the variable responses as germination percent, phenology and biomass at seeding stage. Results demonstrate that germination and growing, were enhanced by the $B$. cereus and $P$. polymixa, by the invading inside of the root system protected from negative environmental factors and then by transforming seed exudates into phytohormons to induce rapid germination and healthy growth due to improve the uptake of nitrogen fertilizer to optimize it and avoid applying in excess to preserve soil productivity.
\end{abstract}

Keywords: soil, nitrogen fertilizer, endophytic beneficial bacteria, cereal
Volume 4 Issue 5 - 2020

\author{
Blanca Celeste Saucedo Martinez,' Maria \\ Janet Tena Rodriguez,' Liliana Marquez- \\ Benavides, I Jose Luis Rico Cerda, ${ }^{2}$ Juan \\ Manuel Sánchez-Yáñez,' \\ 'Research Institute of Chemical Biology, Environmental \\ Microbiology Laboratory, Universidad Michoacana de San \\ Nicolás de Hidalgo, Mexico \\ ${ }^{2}$ Department of Chemical Engineer, Universidad Michoacana de \\ San Nicolás de Hidalgo, México
}

\begin{abstract}
Correspondence: Juan M Sánchez-Yañez, Research Institute of Chemical Biology, Environmental Microbiology Laboratory, Universidad Michoacana de San Nicolás de Hidalgo, Mexico, Tel
\end{abstract} 00524433223500, ext.4240,Email syanez@umich.mx

Received: September 27, 2020 | Published: October 13, 2020

\section{Introduction}

The world population is pressing agriculture to increase Oryza sativa (rice) production. Rice is one of the three leading cereals in the world and an important dietary component for more than 3.5 billion people. ${ }^{1}$ Among the nutrients needed by the rice plants, nitrogen $(\mathrm{N})$ as a nitrogen fertilizer (NIFE) is one of the most important. ${ }^{2}$ Due to the intensive agriculture production, the use of NIFE as $\mathrm{NH}_{4} \mathrm{NO}_{3}$ as source is nowadays necessary. ${ }^{3}$ However, the excessive utilization of NIFE in agriculture, decreases organic matter of the soil which is negative for the life of microorganisms living nutrient cycling. ${ }^{4}$ Likewise it was reported that organic matter degradation by applying in excess NIFE affecting the soil microbiota. ${ }^{5}$ In addition, up to $70 \%$ of the NIFE supplied to rice fields is lost, which causes a high negative impact to the environment. ${ }^{6-8}$ Currently bacterial inoculants are receiving special attention due to their positive effects in agriculture that can mitigate the environmental problems caused by the excessive use of NIFE. In that sense plant growth promoting bacteria (PGPB) transforming seed and root exudates into phytohormones which play an important role in NIFE availability to plants, PGPB are extensively distributed among Bacteria and Archaea domains. ${ }^{9}$ Previous reports also indicate that the rice production can be enhanced by the use PGPB to reduce and to optimize a NIFE consumption. Das and Saha,${ }^{10}$ conducted a field experiment of rice seeds inoculated with Azotobacter strain AS8 and Azospirillum strain AM1, both PGPB, with $50 \mathrm{~kg}$ of N as $\mathrm{NH}_{4} \mathrm{NO}_{3}$ to improve NIFE uptake in the rhizosphere of rice. The authors found that both PGPB substantially increased the availability of NIFE in the rhizosphere, leading to raise crop yield of rice, due to efficiency of Azotobacter strain AS8 better than Azospirillum strain AM1. In another study, Biswas et al. ${ }^{11}$ reported the inoculation of Pankaj rice seeds with six PGPB and found that certain strains of Rhizobium can enhance rice grow. The authors also concluded that these positive effects are most due, to mechanisms that involve phytohormones in seed germination and health growth root physiology at reduced dose of NIFE. García de Salamone et al. ${ }^{12}$ also performed a rice field study by inoculation of seeds with two strains Azospirillum brasilense, and found that inoculation increased aerial biomass at the tillering and grain-filling stages. Although the authors found an increase in $\mathrm{N}$ content in rice plants by 16 and $50 \mathrm{~kg} / \mathrm{ha}$, Yanni and Dazzo, ${ }^{13}$ assessed the inoculation of rice seeds with Rhizobium leguminosarumbvtrifolii. The authors performed single of multi-strain consortia inoculation with 7 strains on 5 varieties of rice, during 5 growing seasons. An average grain-yield increase of $19.5 \%$ was observed. In that sense, the aim of this research was to analyse the effect of endophytic $B$. cereus and $P$. polymxya in the germination adn growth of $O$. sativa at $50 \%$ of $\mathrm{NH}_{4} \mathrm{NO}_{3}$.

\section{Experimental}

\section{Isolation and culture of B. cereus and P. polymxya}

Leonard jars, were prepared with soil sieved using a mesh No. 20 , then soil was exposed to the sunrays during $48 \mathrm{~h}$. The soil was then sterilized and $1 \mathrm{~kg}$ of treated soil was placed in the upper vessel, whereas the lower vessel of $900 \mathrm{ml}$, was completed filled with water or with a mineral solution (MS) containing $\mathrm{NH}_{4} \mathrm{NO}_{3}$. The chemical composition of the MS was the following, in $\mathrm{g} / \mathrm{L}$ : $\mathrm{KH}_{2} \mathrm{PO}_{4}, 3.0$; $\mathrm{K}_{2} \mathrm{HPO}_{4}, 3.5 ; \mathrm{MgSO}_{4}, 1.5 ; \mathrm{CaCl}_{2}, 0.1 ; \mathrm{FeSO}_{4}, 0.5$; and $1.0 \mathrm{ml} / \mathrm{L}$ of a trace metal solution $\left(\mathrm{H}_{3} \mathrm{BO}_{3} 2.86 ; \mathrm{ZnSO}_{4} .7 \mathrm{H}_{2} \mathrm{O} 0.22 ; \mathrm{MnCl}_{2} .7 \mathrm{H}_{2} \mathrm{O}\right.$ $1.81 ; \mathrm{K}_{2} \mathrm{MnO}_{4}, 0.09$, as $\mathrm{N}$ source, this MS contained either 30 or 15 $\mathrm{g} / \mathrm{L}$ of $\mathrm{NH}_{4} \mathrm{NO}_{3}$. The endophytic strains of $B$. cereus and $P$. polymxya were isolated from the root system of Zea mays var mexicana (teocintle well known maize ancestor). Since both were forming spores to active them, each of them was suspended in $3 \mathrm{ml}$ of a saline solution at $0.85 \%$ of $\mathrm{NaCl}$ and $0.01 \%$ of commercial detergent, at 72 ${ }^{\circ} \mathrm{C}$ for $10 \mathrm{~min}$. B. cereus and $P$. polymxya were cultivated in agar plates containing $(\mathrm{g} / \mathrm{L})$ : meat extract, 3.0; gelatine peptone, 5.0; agar-agar, 15; at $\mathrm{pH}$ of 7 , plate was incubated at $32^{\circ} \mathrm{C} / 24 \mathrm{~h}$. 
Antibiotic marks in endophytic $B$. cereus and $P$. polymyxa to detect colonization of O. sativa

The colonization of endophytic $B$. cereus and $P$. polymyxa, inside of the tissues of $O$. sativa,was evaluated starting with the method proposed by Kirby-Bauer ${ }^{14}$ by using the maximum antibiotic concentration of $102 \mu \mathrm{g} \mathrm{mL}^{-1}$ of ampicillin and $23.2 \mu \mathrm{g} \mathrm{mL}^{-1}$ of tetracycline for $B$. cereus in nutrient agar. Contrarily, $5.6 \mu \mathrm{g} \mathrm{mL}^{-1}$ and $15.0 \mu \mathrm{g} \mathrm{mL} \mathrm{m}^{-1}$ of the same antibiotics were utilized in nutrient agar for $P$. polymyxa and thiabendazole in both cases, to avoid the growing of fungi. To assure that mutation was no occurred during antibiotic treatment and to proof the atmospheric $\mathrm{N}_{2}$-fixation capacity of P. polymyxa, was also cultivated in a Burk medium containing, in $\mathrm{g} / \mathrm{L}$ : glucose, $10.0 ; \mathrm{KH}_{2} \mathrm{PO}_{4}, 2.0 ; \mathrm{MgSO}_{4}, 3.0$; and $1 \mathrm{ml}$ of trace metal solution in $\mathrm{g} / \mathrm{l}: \mathrm{H}_{3} \mathrm{BO}_{3}, 2.86 ; \mathrm{ZnSO}_{4} .7 \mathrm{H}_{2} \mathrm{O}, 0.22 ; \mathrm{MnCl}_{2} .7 \mathrm{H}_{2} \mathrm{O}, 1.81$; $\mathrm{KMnO}_{4}, 0.09$; bromothymol blue, 10 ; agar, 18.0 , the $\mathrm{pH}$ was adjusted to 7.5 .

\section{Inoculation of rice seeds with endophytic $B$. cereus and P. polymyxa}

The rice seeds were disinfected with a sodium hypochlorite solution $(1 \% \mathrm{v} / \mathrm{v})$ during $5 \mathrm{~min}$. The seeds were fivefold rinsed with sterilized water, then in ethanol solution at $75 \%$ during $5 \mathrm{~min}$ and rinsed sixfold with sterilized water (Table 1). Then $1 \mathrm{~mL}$ of each in saline solution at $85 \%$ containing the harvested bacteria grew in agar, were separately inoculated on 20 rice seeds previously disinfected. For co-inoculation of $B$. cereus and $P$. polymyxa, $0.5 \mathrm{~mL}$ of each solution were well-mixed and then inoculated on 20 rice grains. The sowing and growing of the seeds occurred in Leonard jars, fed with MS and $\mathrm{NH}_{4} \mathrm{NO}_{3}$ was applied. for instance, seeds inoculated with $B$. cereus or $P$. polymyxa or both, and fed with $\mathrm{MS}$ and $\mathrm{NH}_{4} \mathrm{NO}_{3}$ were performed and labelled as a $B$. cereus or $B$. cereusand $P$. polymxya, respectively. In addition, an absolute control (AC) of non-inoculated seeds sowing and irrigated with water; whereas non-inoculated seeds fed with a MS containing $\mathrm{NH}_{4} \mathrm{NO}_{3}(30$ and $15 \mathrm{~g} / \mathrm{L})$ were referred as a relative control, RC-1 and RC-2, respectively. Table 1 shows the experimental conditions used in each assay.

\section{Recovering of endophytic $B$. cereus and P. polymyxa from O. sativa tissues}

Four seeds of $O$. sativa were sowing for the determination of endophytic $B$. cereus and $P$. polymyxa were utilized in each treatment. Two seeds inoculated with $B$. cereus were rinsed with sterilized water and afterwards $1 \mathrm{~g}$ of tissue from leaves, stem and root were obtained and separately suspended in $5 \mathrm{~mL}$ o saline solution to strike on nutrient agarwith the maximum ampicillin and tetracycline concentrations. In the case of the tissues of $O$. sativa inoculated with $P$. polymyxa, a similar procedure was followed, except that the saline solution contains the required maximum ampicillin and tetracycline concentrations determined for P. polymyxa. However, for co-inoculated with endophytic B. cereus and P. polymyxa, the tissue suspension in $5 \mathrm{~mL}$ of a solution which contains $2.5 \mathrm{~mL}$ of each bacteria. From each solution of tissue, $2.5 \mathrm{~mL}$ were incubated at $32^{\circ} \mathrm{C}$ for $24 \mathrm{~h}$. The remaining $2.5 \mathrm{~mL}$ were pasteurized at $72^{\circ} \mathrm{C}$ for $10 \mathrm{~min}$, cooled in an ice bath during $5 \mathrm{~min}$ and finally incubated at $32{ }^{\circ} \mathrm{C}$ for $24 \mathrm{~h}$. The tissue from the leaves, stem and roots of the remaining from each treatment were extracted, separately disinfected with sodium hypochlorite solution $(1 \% \mathrm{v} / \mathrm{v})$ and then rinsedwith sterilized water $1 \mathrm{~g}$ of disinfected tissue was ground in a mortar with $9 \mathrm{~mL}$ of saline solution at $0.85 \%$ from this solution, $1 \mathrm{~mL}$ was added into $4 \mathrm{ml}$ of the corresponding nutrient agar with antibiotics, or in a mixture of both bacteria on nutrient agar as in the case of co-inoculation. From this suspension, $2.5 \mathrm{~mL}$ were directly incubated at $32^{\circ} \mathrm{C}$ for $24 \mathrm{~h}$ and the remaining was pasteurized prior to incubation, at similar experimental conditions. The CFU was determined for each tissue incubated culture. The response parameters for measured the effect of $B$. cereus and $P$. polymxya on $O$. sativa were the germination percentage, at seedling and flowering stage by the phenology: plant height, radical length, biomass: fresh, dry, areal and radical weights were determined. The experimental data were evaluated using ANOVA/Turkey software $(\mathrm{P}<0.05)$

\section{Results}

Table 1 summarised the experimental design followed with $O$. sativa inoculated with endophytic B. cereus and P. polymyxa.

Table 2 showed the effects of inoculation on the phenology at seedlings stage. This table indicates that percentage of germination, evaluated 10 days after inoculation was better in rice seeds with endophytic $B$. cereus. Moreover, O. sativa at dose of $30 \mathrm{~g} / \mathrm{L} \mathrm{ofNH}_{4} \mathrm{NO}_{3}$ instead of $15 \mathrm{~g} / \mathrm{L}$ (relative control-1 and relative control-2 respectably) enhanced the phenology and biomass weight of $O$. sativa. However, comparing with $O$. sativa as a relative control -2 with those results obtained, which were grown with half dose of $\mathrm{NH}_{4} \mathrm{NO}_{3}$, the improving achieved by $B$. cereus is remarkable. The inoculation with $B$. cereus and co-inoculation with $B$. cereus and $P$. polymyxa showed the best results, improving plant high, radial length and biomass weight. The phenology parameters using $P$. polymyxa as inoculant, were also enhanced compared to those observed with non-inoculation $O$. sativa used as a relative control.

The density of endophytic $B$. cereus and $P$. polymyxa in rice seedlings, after inoculation was performed and the results are showed in Table 3. The location of both genus in the seedling was evaluated, this demonstrates that inoculation with endophytic B. cereus and $P$. polymyxa indeed, enhanced the growing of rice seeds. Independently of disinfection, and pasteurization of $O$. sativa, the absence of $B$. cereus and $P$. polymyxa in leaves is clearly observed in this table. This indicates the positive effect of endophytic B. cereus and/or $P$. polymxya on the growth of $O$. sativa with these bacteria, is centred on stem and roots due that both bacteria colonized these specific tissues of the plant because the organic compound produced by photosynthesis which does not exist in leaves tissue. Comparing the results presented in Table 3 related to stem and roots, the most remarkable effect is observed in roots of the non-disinfected, non-pasteurized rice, which showed a density of both of them around 251 and $270 \times 10^{6} \mathrm{CFU} / \mathrm{g}$, when the seeds were inoculated just with $B$. cereus alone as well as only with $P$. polymxya and with both bacteria, respectively. It is worth therefore that disinfection and pasteurization of the $O$. sativa seeds, showed negative effects. The information related to the inoculation of $B$. cereus and P. polymyxa is scarce, especially when the beneficial effect is due to an invasion of the root system and the stem to take advantage of metabolites of photosynthesis in phytohormons that increased the capacity of rice for optimization of NIFE and consequently now there is an better option for healthy plant growth for O. sativa production. ${ }^{15,16}$

The rice growing enhancement resulted after inoculation,was in agreement with other studies that reportedthe inoculation of rice seeds with other genus of plant growth promoting bacteria different than $B$. cereus and P. polymyxa depends its capacity to transform organic metabolites from steam and root metabolism into phytohormons for enhancing uptake radical absorption of NIFE reduced at $50 \%$ dose which avoiding soil losing productively and surface and underground pollution by the runoff of NIFE applying in excess. ${ }^{11-13}$ 
Table I Experimental design of the effect of endophytic Bacillus cereus and Paenibacillus polymyxaon Oriza sativa

\begin{tabular}{|c|c|c|c|c|c|c|}
\hline Treatments & O. sativa & B. cereus & P. polymyxa & \multicolumn{2}{|c|}{ NH4NO3 in mineral solution } & Water \\
\hline Absolute control & + & - & - & $'-$ & - & + \\
\hline Relative control-I & + & - & - & + & - & - \\
\hline Relative control-2 & + & - & - & - & + & - \\
\hline Paenibacillus polymyxa & + & - & + & - & + & - \\
\hline B. cereus+P.polymyxa & + & + & + & - & + & - \\
\hline
\end{tabular}

Table 2 Effect of endophytic Bacillus cereus and Paenibacillus polymyxa in germination and seedlings stage of Oriza sativa with mineral solution and $\mathrm{NH}_{4} \mathrm{NO}_{3}$ at $50 \%$ dose

\begin{tabular}{|c|c|c|c|c|c|c|c|}
\hline \multirow[b]{2}{*}{ Treatment* Oriza sativa } & \multirow{2}{*}{$\begin{array}{l}\text { Germination, \% } \\
\text { ( } 10 \text { days after } \\
\text { inoculation) }\end{array}$} & \multicolumn{2}{|c|}{ Phenology (cm) } & \multicolumn{4}{|c|}{ Biomas weight (g) } \\
\hline & & $\begin{array}{l}\text { Plant } \\
\text { height }\end{array}$ & $\begin{array}{l}\text { Radical } \\
\text { length, }\end{array}$ & $\begin{array}{l}\text { Fresh } \\
\text { aerial }\end{array}$ & $\begin{array}{l}\text { Fresh } \\
\text { radical }\end{array}$ & $\begin{array}{l}\text { Dry } \\
\text { aerial }\end{array}$ & $\begin{array}{l}\text { Dry } \\
\text { radical }\end{array}$ \\
\hline Absolute control (water) & $77 f^{* *}$ & $27.9 \mathrm{lb}$ & $13.75 \mathrm{a}$ & $0.17 b$ & $0.12 d$ & $0.02 b$ & $0.01 \mathrm{c}$ \\
\hline Relative control-I (NIFE I00\%) & $8 \mathrm{le}$ & $25.42 b$ & $12.17 \mathrm{a}$ & $0.23 a$ & $0.23 b$ & $0.03 a$ & $0.05 a$ \\
\hline Relative control-I (NIFE 50\%) & $91 \mathrm{~b}$ & $22.92 c$ & $9.08 \mathrm{~b}$ & $0.17 b$ & $0.14 c$ & $0.02 b$ & $0.02 b$ \\
\hline B. cereus NIFE $50 \%$ & $93 a$ & $32.15 a$ & $14.33 \mathrm{a}$ & $0.24 \mathrm{a}$ & $0.28 \mathrm{a}$ & $0.03 a$ & $0.02 b$ \\
\hline P. polymyxa NIFE $50 \%$ & $88 c$ & $28.4 \mathrm{Ib}$ & $9.91 \mathrm{~b}$ & $0.22 \mathrm{a}$ & $0.17 b$ & $0.03 a$ & $0.02 b$ \\
\hline B.cereus/P.polymxya NIFE 50\% & $88 c$ & $27.68 b$ & $12.25 \mathrm{a}$ & $0.23 a$ & $0.19 b$ & $0.03 a$ & $0.05 a$ \\
\hline
\end{tabular}

Table 3 Distribution and density of vegetative and sporulation cells of endophytic Bacillus cereus y Paenibacillus polymyxa in the tissue of Oriza sativa

\begin{tabular}{|c|c|c|c|c|c|c|}
\hline \multirow{3}{*}{\multicolumn{2}{|c|}{ Treatment of $O$. sativa }} & & \multicolumn{4}{|c|}{ CFU x I06/g tissue ofO. sativa } \\
\hline & & & \multirow[t]{2}{*}{ B. cereus } & \multirow[t]{2}{*}{ P. polymyxa } & \multicolumn{2}{|c|}{ B. cereus+P.polymyxa } \\
\hline & & & & & B. cereus & P. polymyxa \\
\hline \multirow{6}{*}{ Non-disinfected } & \multirow{3}{*}{ Non-Pasteurization } & Leaves & 0 & 0 & 0 & \\
\hline & & Stem & 40 & 31 & 22 & 33 \\
\hline & & Roots & 251 & 135 & 180 & 90 \\
\hline & \multirow{3}{*}{ Pasteurization } & Leaves & 0 & 0 & 0 & \\
\hline & & Stem & 43 & 36 & 18 & 25 \\
\hline & & Roots & 62 & 34 & 27 & 39 \\
\hline \multirow{6}{*}{ Disinfected } & \multirow{3}{*}{ Non-Pasteurization } & Leaves & 0 & 0 & 0 & \\
\hline & & Stem & 25 & 23 & 19 & 24 \\
\hline & & Roots & 28 & 17 & 0 & 58 \\
\hline & \multirow{3}{*}{ Pasteurization } & Leaves & 0 & 0 & 0 & \\
\hline & & Stem & 35 & 29 & 0 & \\
\hline & & Roots & 33 & 44 & 48 & 22 \\
\hline
\end{tabular}

\section{Conclusion}

The inoculation and co-inoculation of $O$. sativa with endophytic $B$. cereus and $P$. polymyxa is here in reported. The results indicated an improvement on the rice growth, dueits capacity of these endophytic bacteria mainly located in the stem and roots. Interestingly, the enhancement in the growing of $O$. sativa showed that $50 \%$ of $\mathrm{NH}_{4} \mathrm{NO}_{3}$ could be optimized by the activity of these endophytic PGPB with beneficial effect for the environment since hyper-fertilization could be avoided.

\section{Acknowledgments}

To Grant Project 2.7 of the CIC-UMSNH (2020) Morelia, Michoacán, México, BIONUTRA, SA de CV, Maravatio, Michoacán México, for the support on this publication.

\section{Conflicts of interest}

Authors declare no conflict of interest exists. 


\section{References}

1. Pittol ML, Durso V, H Valiati, et al. Agronomic and environmental aspects of diazotrophic bacteria in rice fields. Ann Microbiol. 2016;66(2):511-527.

2. Chen LS, Wang K. Diagnosing of rice nitrogen stress based on static scanning technology and image information extraction. J Soil Sci Plant Nutr. 2014;14:382-393

3. Cai Z, Shan Y, Xu H. Effects of nitrogen fertilization on $\mathrm{CH} 4$ emission from rice fields. Soil Sci Plant Nutr. 2007;53:353-361.

4. Guo JH, Liu XJ, Zhang Y, et al. Significant acidification in major Chinese crop lands. Science. 2010;327:1008-1010.

5. Fierer N, and Jackson RB. The diversity and biogeography of soil bacterial communities. Proc Natl Acad Sci USA. 2006;103:626-631.

6. Ghosh BC, Bhat R. Environmental hazards of nitrogen loading in wetland rice fields. Environ Pollut. 1998;102:123-126,

7. Fageria NK, Baligar VC. Lowland rice response to nitrogen fertilization. Commun Soil Sci Plant An6al. 2007;32:1405-1429.

8. Zhang Y-Q, Wen M-X, Li X-P, et al. Long-term fertilisation causes excess supply and loss of phosphorus in purple paddy soil. J Sci Food Agric. 2013;94:1175-1183.

9. Xie J-B, Du Z, Bai L, et al. Comparative genomic analysis of N2-fixing and non-N2- fixing Paenibacillus spp.: organization, evolution and expression of the nitrogen fixation genes. Plos Genet. 2014;10:e1004231.

10. Das AC, Saha D. Effect of diazotrophs on the mineralization of organic nitrogen in the rhizospheresoils of rice (Oryza sativa). J Crop Weed. 2007;3:47-51.

11. Biswas JC, Ladha JK, Dazzo FB. Rhizobia inoculation improves nutrient uptake and growth of lowland rice. Soil Sci Soc Am J. 2000;64:1644 1650 .

12. García de Salamone IE, Di Salvo LP, Ortega JSE, et al. Field response of rice paddy crop to Azospirillum inoculation: physiology of rhizosphere bacterial communities and the genetic diversity of endophytic bacteria in different parts of the plants. Plant Soil. 2010;336:351-362.

13. Yanni YG and Dazzo FB. Enhancement of rice production using endophytic strains of Rhizobium leguminosarum bv. trifolii in extensive field inoculation trials within the Egypt Nile delta. Plant Soil. 2010;336:129-142,

14. Hudzicki J. Kirby-bauer disk diffusion susceptibility test protocol. American Society for Microbiology. 2016;1-23.

15. Mumtaz MZ, Malik A, Nazl F, et al. Potential of zinc solubilizing bacillus strains to improve growth, yield, and quality of maize (Zea mays). 2010.

16. Younas A, HA Sadaqat, $M$ Kashif, et al. Combiningability and heterosis for grainironbiofortification in bread wheat. J Sci Food Agric. 2020;100:1570-1576. 